$\mathrm{Cu}(110)-0(2 \times 1)$
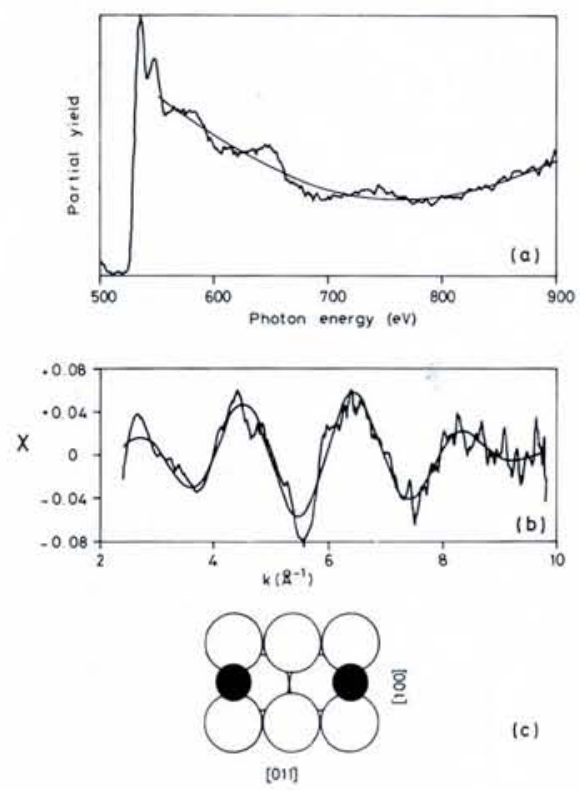

Fig. 7 - SEXAFS-signal before (a) and after (b) background subtraction of oxygen adsorbed on a $\mathrm{Cu}(110)$ single crystal together with the surface structure model (c) (U. Döbler et al., Phys. Rev. Lett. 52 (1984) 1437).

Fig. 7 shows the SEXAFS signal before (a) and after (b) background subtraction of oxygen adsorbed on a copper (110) single crystal. From these data, a bond length of $1.85 \AA$ between oxygen and copper atoms has been determined. The polarisation dependence of the SEXAFS signal indicates that the oxygen atoms sit in bridge sites along the [100] direction and are located $0.3 \AA$ above the $\mathrm{Cu}(110)$ surface (Fig. 7c).

\section{Summary}

BESSY, the German Federal Republic's national synchrotron radiation source for the VUV and soft X-ray regions, is currently in its second year of user operation. In this article we have described some of the experiments in progress and attempted to show how the properties of synchrotron radiation can be exploited in this highly topical area of research.

\section{REFERENCES}

1. Eastman D.E. and Himpsel F.J., Physics Today 641981 May.

2. Lee P.A., Citrin P.H., Eisenberger P. and Kincaid B.M., Rev. Mod. Phys. 53 (1981) 769.

3. Menzel D. and Gomer R., J. Chem. Phys. 41 (1964) 3311; Readhead P.A., Can. J. Phys. 42 (1964) 886.

4. Kunz C. (ed.), Synchrotron Radiation: Techniques and Applications (Springer Verlag, Berlin) 1979.

\title{
TEACHING ABROAD
}

\section{Franciszek Kaczmarek, Poznan}

\author{
Under the Teaching Abroad Scheme of the European Physical Society. \\ organized through the Physics Education Committee, Professor Kacz- \\ marek has spent two months at Lund University participating in the \\ faculty life there. He presents here a few of his impressions.
}

On the invitation of Professor Indrek Martinsson and Professor Hans Ryde of Lund University I spent two months (September and October 1983) in the Department of Physics of Lund University. Although the main goal of my visit was to become familiar with the teaching in Lund and to take an active part in selected teaching activities, I had also the opportunity to see the research work at the Institute of Technology and within the Atomic Spectroscopy Group where the very well equipped laboratories create a solid base for good spectroscopic investigations. It should also be noted that practical applications of modern spectroscopy methods in air pollution measurements, in treating tumours and in many other fields appeared surprisingly well developed. However, I was mainly associated with the educational group of Ingmar Johansson and I spent many hours in the student laboratories, especially during their introductory exercises and later on when they performed more advanced experiments.

As in Poland, where, for example, the number of freshmen entering the physics faculty in the University in Poznan is 40-50 a year, it would seem that physics studies are not very popular in Sweden. The period when almost everybody was excited by the spectacular achievements in physics appears to be over and the youth is more pre-occupied by the possible world disaster which - indirectly - may come from physics. Moreover, it is now very hard to find jobs for physicists in industry and research laboratories.

There are important differences between the Lund schedule and our schedule in Poznan. For example, the basic physics course in Poznan is spread over a two-year period at the rate of about four lectures plus two numerical exercises per week. In Lund, the basic course also takes two years, but $50 \%$ is mathematics. During the physics part, the number of lessons is about 16/week of which some are numerical exercises. In some weeks, the lecturing gives place to laboratory work; this occupies the equivalent of three full days in any week. The practical part of the Lund education programme consists of an Introductory
Laboratory (16 experiments performed within several days), followed by Normal Laboratory with simple and more advanced experiments, and special tasks performed in research laboratories concerned with, for example, Compton scattering, bubble chambers, Ca-spectrum, beam foil spectroscopy, optical pumping, etc. By comparison, in the Polish system we have Physics Laboratory I, first year students, four hours a week over one year - Physics Laboratory II - six hours a week over one year during the second and the third year of studies - and also special tasks performed at various research laboratories.

I did not find the Swedish students to be much different from our own students except they had a much higher proficiency in English and, to my surprise, their discipline regarding lectures was unbeliveably impressive as compared to the situation in Poland. It is rather normal that about $50 \%$ of the student body do not attend lectures at our University and furthermore, some of them do not make use of their time that is devoted to lectures.

There is another important difference between the Swedish and Polish education process. Many faculty members in our country feel that a greater than ordinary teaching activity is not properly appreciated. Promotion very rarely owes a great deal to special educational work because it mainly, or solely, depends on the research record. A very good teacher has, in practice, no chance of being promoted or even of keeping his position for a long time. However, discussion on this problem has been going on now for the past year (with no practical results as yet). Nevertheless, this is not the main reason why some faculty members do not pay enough attention to teaching.

In contrast, I have found in Lund a large group of people approaching their teaching work with extraordinary involvement, very sensitive to the students' problems and trying to make the eduction as rewarding as possible. Consequently, being in Lund I had the occasion to see good research and effective teaching activities taking place together. This was for me a most encouraging experience. 